\title{
Pagamento por Desempenho na Atenção Primária à Saúde em Curitiba-PR: Incentivo ao Desenvolvimento da Qualidade
}

\author{
Thabata Cristy Zermiani \\ Professora Mestre da Pontifícia Universidade Católica do Paraná, \\ Curitiba, Paraná, Brasil \\ thabata.zermiani@gmail.com \\ Marcia Helena Baldani \\ Professora Doutora da Universidade Estadual de Ponta Grossa, \\ Ponta Grossa, Paraná, Brasil \\ marciabaldani@gmail.com \\ Rafael Gomes Ditterich \\ Professor Doutor da Universidade Federal do Paraná, \\ Curitiba, Paraná, Brasil \\ prof.rafaelgd@gmail.com
}

Resumo O objetivo desse estudo foi descrever e discutir a percepção dos trabalhadores da saúde no município de CuritibaPR, Brasil, sobre o uso de incentivos profissionais como ferramenta na gestão e organização da Atenção Primária à Saúde. Para tanto, realizou-se um estudo de caso descritivo com abordagem qualiquantitativa. A análise dos dados buscou compreender o impacto da utilização de incentivos financeiros na organização da Atenção Primária à Saúde em CuritibaPR. Concluiu-se que a avaliação de desempenho com uso de incentivos oferecidos aos trabalhadores foi importante para ampliar a motivação e comprometimento dos profissionais de saúde com a qualidade do trabalho e o alcance de metas pactuadas. Entretanto, foram identificadas dificuldades em relação ao processo avaliativo, à priorização da quantidade e ao fato de os incentivos serem empregados como manobra para não aumentar os salários dos servidores.

Palavras-chave: Administração de serviços de saúde, gestão em saúde, gestão do desempenho em saúde, incentivos, pagamento por desempenho. 


\section{Introdução}

Com a Reforma da Administração Pública, diferentes ferramentas de gestão passaram a ser implantadas, como a contratualização de resultados e o pagamento por desempenho, visando a ampliar a efetividade, a eficiência e a eficácia dos serviços públicos (Ditterich; Moysés; Moysés, 2012).

Fekete e Almeida (2000), definem os sistemas de incentivo como componentes da estratégia de gestão que, aplicados a partir de uma remuneração básica, têm o propósito de estimular a equipe de trabalho, otimizando os componentes do processo produtivo e possibilitando o alcance dos objetivos organizacionais e a ampliação da qualidade. $O$ pagamento por desempenho (pay for performance - P4P) pode ocorrer de formas variadas, como aquele feito de acordo com a realização de certos procedimentos ou ainda indicadores referentes às condições de saúde de grupos específicos (Poli Neto et al., 2016).

Os países membros da Organização de Cooperação e Desenvolvimento Econômico (OCDE) têm adotado o pagamento por desempenho desde a década de 1980 (OCDE, 2005). A implantação dos incentivos financeiros propicia a disseminação das metas pactuadas, o preenchimento adequado do sistema de informação, o monitoramento das ações desenvolvidas e a busca por estratégias para atingir os objetivos estabelecidos (Costa e Silva; Escoval; Hortale, 2014). Trata-se, portanto, de um instrumento útil para motivar os profissionais, que pode estimular o desenvolvimento de atividades que somente o vínculo trabalhista não conseguiria atingir (Poli Neto et al., 2016). Entretanto, sua aplicação deve ser realizada de forma cautelosa, com planejamento prévio, estabelecendo o agente-alvo do sistema, as metas a serem atingidas, a forma de monitoramento e avaliação, a modalidade de recompensa, e os fatores institucionais que podem influenciar nos resultados (Barreto, 2015).

O pagamento por desempenho pode gerar também efeitos indesejáveis, como: comportamentos não intencionais; distorções, ignorando tarefas importantes não recompensadas; fraudes nos relatórios; corrupção;seleção de casos de pacientes que permitam atingir as metas mais rapidamente; dependência dos incentivos financeiros; desmoralização; burocracia; e diluição da motivação intrínseca dos profissionais (Oxman; Fretheim, 2009).

No Brasil, os municípios têm adotado diferentes formas de organização da atenção e de modelos de gestão. No âmbito da gestão por resultados, o uso de incentivos financeiros tem angariado interesse, inclusive como política do Ministério da Saúde, existindo algumas experiências em curso no país. Em Curitiba-PR, a Secretaria Municipal de Saúde (SMS) formulou no ano de 2002 o Contrato Interno de Gestão na Atenção Primária, o qual foi denominado Termo de Compromisso de Gestão (TERCOM) (Azevedo, 2009). Para tanto, foram realizadas consultorias e oficinas com profissionais e gestores, nas quais foram estabelecidos os indicadores e metas para monitoramento que iriam compor o Plano Operativo Anual (POA), anexo ao TERCOM (Marty, 2009).

Em 2003, houve a sua implementação juntamente com uma política de remuneração variável, o Incentivo ao Desenvolvimento da Qualidade (IDQ), como 
forma de motivar os profissionais de saúde para ampliar a qualidade dos serviços (World Bank, 2006). O IDQ permaneceu em vigor até o início de 2015. Dos 74 indicadores que compunham o POA, 13 faziam parte do IDQ, sendo que as gratificações recebidas pelos funcionários que apresentavam bom desempenho variavam de 20 a $50 \%$ sobre o seu salário-base (Ducci, 2007).

O IDQ era avaliado trimestralmente por uma equipe de gestão de recursos humanos da SMS de Curitiba, por meio de quatro planilhas: avaliação individual do profissional da saúde, com peso de 45\%, a qual era realizada pela chefia imediata, analisando o conhecimento do trabalho, a postura profissional, o relacionamento, a qualidade do trabalho, entre outros fatores; a autoavaliação, com peso de 5\%, realizada pelo próprio profissional; a avaliação da unidade de saúde, com peso de 35\%, realizada por meio do monitoramento do alcance das metas fixadas no POA e nas metas administrativas; e a avaliação da comunidade, com ponderação de $15 \%$, por meio de pesquisa externa sobre o grau de satisfação da população atendida na Unidade (World Bank, 2006; Ditterich; Moysés, 2012; Azevedo; Faoro; Xavier, 2013).

Ao final das avaliações era gerado um relatório com as notas, o qual era validado por uma comissão de monitoramento. Em seguida, era realizada uma devolutiva aos servidores, tendo direito à remuneração variável aqueles com pontuação igual ou superior a 80 pontos na avaliação individual e na composição do resultado final. Havia ainda fatores administrativos excludentes, que incluíam faltas, penalidades e atrasos (Azevedo; Faoro; Xavier, 2013).

O IDQ vigorou até o início de 2015, ano em que foi assinado o Decreto $\mathrm{n}^{\circ} 298$, o qual instituiu as Gratificações Especiais de Difícil Provimento e de IDQ Residual, revogando o IDQ na SMS de Curitiba. O IDQ Residual corresponde ao valor fixo e nominal da diferença percebida na comparação de valores recebidos individualmente pelo servidor, nos meses de Novembro e Dezembro de 2014. Esta gratificação seria mantida até a instituição de um novo Programa de Remuneração Variável da SMS (Curitiba, 2015a). Na mesma data foi publicado o Decreto $n^{\circ} 299$, que criou uma gratificação especial em substituição ao IDQ para as funções de gestão (Curitiba, 2015b). Em 2015 foram deflagradas greves pelos profissionais de saúde da SMS de Curitiba devido ao não pagamento de acordos salariais e do IDQ residual (Scortecci, 2015).

O fim do IDQ pode estar associado a alguns aspectos, como: o fato de não estar mais gerando os efeitos esperados, tendo se tornado apenas mais uma gratificação no salário; ou ainda devido à descontinuidade política que, por vezes, implica no fim de programas e ações, devido ao fato de outro grupo político, com outras concepções e ideologias, ter assumido o poder. Os contratos de gestão e o sistema de incentivo foram adotados em Curitiba em um momento em que era priorizada a gestão por resultados e mecanismos de contratualização, e assim permaneceu até 2012. Durante este período, prevaleceu a vertente econômica-administrativa. A partir de 2013 passou-se a dar maior ênfase à cogestão e à vertente participativa.

Como forma de reestruturação do IDQ, em 2014, foi apresentada nova proposta que foi denominada Qualifica SUS. Na minuta do decreto que instituiria esse incentivo, propôs- 
se que a nova gratificação corresponderia a $10 \%$ do vencimento básico de cada servidor (Curitiba, 2014). Até o presente momento não houve a implantação do Qualifica SUS.

Embora o IDQ já tenha sido findado, a análise da forma como foi implantado e dos resultados obtidos pode ensinar importantes lições e apontar algumas perspectivas para os sistemas de incentivos futuros. Além disso, trata-se de uma das experiências pioneiras no âmbito da administração pública a da Atenção Primária à Saúde no Brasil e ainda são escassos os estudos sobre esta temática. Desta forma, o objetivo deste estudo consistiu em descrever e discutir a percepção dos gestores locais (Autoridades Sanitárias Locais ASL) e dos trabalhadores das equipes básicas de saúde (médicos, enfermeiros, cirurgiõesdentistas) do município de Curitiba-PR, Brasil, quanto à operacionalização do programa de Incentivo ao Desenvolvimento da Qualidade (IDQ) como ferramenta na organização da Atenção Primária à Saúde, identificando suas potencialidades e limitações.

\section{Materiais e métodos}

Este estudo de caso descritivo apresenta abordagem quantitativa e qualitativa. Em um primeiro momento, foi aplicado um questionário, reproduzindo a metodologia utilizada em 2005, em pesquisa realizada pelo Banco Mundial (2006), que estudou inovações em gestão no Brasil, incluindo a gestão hospitalar em São Paulo e a gestão dos cuidados primários à saúde no município de Curitiba. A pesquisa do Banco Mundial avaliou a percepção dos profissionais de saúde que atuavam na Atenção Primária, sobre o uso e aplicabilidade do contrato interno de gestão (TERCOM) e sobre o Incentivo ao Desenvolvimento da Qualidade (IDQ).

Em sua etapa quantitativa, em parceria com a Secretaria Municipal de Saúde, foram entregues questionários estruturados para servidores municipais (autoridades sanitárias locais, médicos, cirurgiões-dentistas e enfermeiros) de 34 Unidades de Saúde do município de Curitiba, distribuídas em cinco Distritos Sanitários (Matriz, Boa Vista, Portão, Cajuru e Boqueirão), entre os meses de agosto e novembro de 2014. A seleção das Unidades de Saúde se deu por meio da consulta ao Cadastro Nacional de Estabelecimentos de Saúde (CNES). Foi realizada uma amostra por conveniência, identificando aquelas que estavam dispostas a participar da pesquisa.

Os instrumentos de coleta de dados foram cedidos à Autoridade Sanitária Local (ASL) de cada Unidade de Saúde, sendo esta convidada a participar da pesquisa e a disponibilizar os questionários aos profissionais de saúde de nível superior atuantes nas respectivas unidades, para o seu preenchimento de forma voluntária, após a assinatura do Termo de Consentimento Livre e Esclarecido (TCLE). Posteriormente os TCLE e os questionários foram recolhidos por um dos pesquisadores envolvidos. Ao todo 148 servidores responderam ao questionário, sendo 24 ASL e 124 profissionais de saúde da Atenção Primária, incluindo médicos (33), enfermeiros (45) e cirurgiões-dentistas (46).A categoria profissional não foi considerada como variável na análise das respostas. 
O critério de exclusão envolveu os servidores que apresentavam menos de um ano de atuação nas Unidades de Saúde, uma vez que era necessário que tivessem se apropriado do sistema de avaliação do desempenho e de incentivo financeiro, com um mínimo de tempo de serviço, para poder interpretar e responder os itens pesquisados.

Posteriormente, entre 2015 e 2016, realizou-se a etapa qualitativa deste estudo. Os profissionais foram selecionados de forma intencional dentre aqueles que responderam ao questionário da fase quantitativa, priorizando os que se mostravam dispostos a participar do estudo e que não estavam em período de férias ou afastados das atividades laborais por motivo de doença.

Não foi preestabelecido o número de participantes que seriam entrevistados na etapa qualitativa, visto que o critério utilizado foi o de se atingir um ponto de saturação. Desta forma, suspendeu-se a inclusão de novos entrevistados a partir do momento em que os dados passaram a ser repetidos, não acrescentando novas informações ao material já obtido (Fontanella; Ricas; Turato, 2008).

Foram definidos alguns critérios para seleção dos entrevistados, a fim de que estes não estivessem concentrados em uma única categoria profissional, em apenas um Distrito Sanitário ou em somente uma Unidade de Saúde. Desta forma, as entrevistas foram ordenadas, selecionando um entrevistado de cada categoria profissional em cada distrito quando possível, uma vez que nem todos dispunham das quatro categorias. Ao concluir as entrevistas, voltava-se ao primeiro distrito até atingir o ponto de saturação.

As entrevistas foram realizadas em horários que não interferiram nos atendimentos dos serviços de saúde aos usuários e em locais afastados do fluxo de pacientes e das interferências dos demais profissionais, assegurando a privacidade de cada participante. Ao todo foram entrevistados 32 servidores, dentre eles: 7 ASL, 9 cirurgiões-dentistas, 10 enfermeiros e 6 médicos, distribuídos em 16 Unidades de Saúde dos 5 Distritos Sanitários supramencionados. As entrevistas ocorreram entre outubro de 2015 e abril de 2016.

Para análise das respostas foi empregada a metodologia do Discurso do Sujeito Coletivo (DSC), a qual é descrita como:

[...] forma qualitativa de representar o pensamento de uma coletividade, o que se faz agregando, num só discurso-síntese, conteúdos discursivos de sentido semelhante emitidos por pessoas distintas, como respostas a perguntas abertas de questionário. Este discurso reunido é uma forma discursiva empírica de produzir, a partir dos depoimentos individuais semelhantes, o pensamento coletivo (Lefévre; Lefévre, 2005, p. 19).

Para tanto, são utilizadas as figuras metodológicas: expressões-chave, ideia central e discurso do sujeito coletivo. Para as respostas individuais de cada questão selecionamse as expressões-chave, que são os trechos mais significativos. A essas expressões-chave correspondem ideias centrais, que são a síntese do conteúdo discursivo manifestado nas expressões-chave. Com o material das expressões-chave de ideias centrais semelhantes, constroem-se discursos-síntese, com número variado de participantes, que são os discursos do sujeito coletivo (DSC). Os resultados desta técnica são apresentados em 
um painel de discursos de sujeitos coletivos, enunciados na primeira pessoa do singular (Lefêvre; Lefêvre, 2005).

O protocolo de pesquisa foi submetido à análise pelo Comitê de Ética em Pesquisa com Seres Humanos, tendo sido aprovado em 07 de agosto de 2013 (CAAE 18110713.0.0000.0102). O Comitê de Ética em Pesquisa (CEP) da Secretaria Municipal da Saúde de Curitiba-PR declarou concordar com o parecer ético emitido pela instituição de ensino.

\section{Resultados}

$\mathrm{Na}$ avaliação dos dados quantitativos obtidos pela aplicação dos questionários aos 148 trabalhadores, o IDQ foi apontado pela maioria (85,8\%) como um instrumento importante na organização do processo de trabalho nas Unidades de Saúde em Curitiba. A maioria dos profissionais considerou que esta ferramenta ainda apresentava efeitos positivos, como redução de faltas e ampliação da motivação, sendo $29,2 \%$ na maioria dos casos e $32,5 \%$ em alguns casos.

$\mathrm{Na}$ Tabela 1, a respeito dos efeitos produzidos pelo IDQ, a maioria identificou que houve diminuição de faltas, atrasos, indisciplina e afastamento. Afirmaram também que houve aumento na motivação e produtividade dos profissionais. Quanto ao impacto sobre os salários, a maioria classificou o aumento como moderado ou substancial. Além disso, identificou-se que houve melhora do trabalho em equipe e aumento da produtividade dos profissionais (Tabela 1).

Tabela 1 - Percepção dos trabalhadores da área da saúde sobre os efeitos produzidos pelo IDQ em Curitiba (2015)

\begin{tabular}{|c|c|c|c|c|c|}
\hline Grau de efeito do IDQ & Nenhum & Mínimo & Moderado & Substancial & Máximo \\
\hline $\begin{array}{c}\text { Diminuiu faltas, } \\
\text { atrasos, indisciplina } \\
\text { e afastamentos }\end{array}$ & $12(8,8 \%)$ & $31(22,6 \%)$ & $36(26,3 \%)$ & $47(34,3 \%)$ & $11(8 \%)$ \\
\hline $\begin{array}{c}\text { Aumentou a motivação } \\
\text { dos profissionais }\end{array}$ & $5(3,6 \%)$ & $30(21,7 \%)$ & $53(38,4 \%)$ & $40(29 \%)$ & $10(7,3 \%)$ \\
\hline $\begin{array}{c}\text { Contribuiu para } \\
\text { aperfeiçoar o processo } \\
\text { de trabalho }\end{array}$ & $6(4,3 \%)$ & $26(18,8 \%)$ & $56(40,6 \%)$ & $44(31,9 \%)$ & $6(4,4 \%)$ \\
\hline $\begin{array}{c}\text { Aumentou o salário } \\
\text { Melhorou o trabalho } \\
\text { em equipe }\end{array}$ & $3(2,2 \%)$ & $25(18 \%)$ & $51(36,7 \%)$ & $41(29,5 \%)$ & $19(13,6 \%)$ \\
\hline $\begin{array}{c}\text { Aumentou a } \\
\text { produtividade dos } \\
\text { profissionais }\end{array}$ & $6(4,4 \%)$ & $16(11,7 \%)$ & $62(45,3 \%)$ & $43(31,3 \%)$ & $10(7,3 \%)$ \\
\hline
\end{tabular}


Sobre o processo avaliativo do IDQ realizado aos servidores (Tabela 2), os profissionais afirmaram que a avaliação individual às vezes levava a uma melhoria de desempenho e que era moderadamente coerente, transparente e imparcial.

Tabela 2 - Percepção dos trabalhadores da saúde sobre o processo de avaliação do IDQ em Curitiba (2015)

\begin{tabular}{|c|c|c|c|}
\hline \multicolumn{4}{|c|}{ Em que medida o processo de avaliação do IDQ é: } \\
\hline Fatores & Minimamente & Moderadamente & Muito \\
\hline Coerente & $28(18 \%)$ & $104(68,7 \%)$ & $20(13,3 \%)$ \\
\hline Transparente & $25(17,3 \%)$ & $84(56,7 \%)$ & $39(26 \%)$ \\
\hline Imparcial & $27(18,2 \%)$ & $99(66,9 \%)$ & $22(14,9 \%)$ \\
\hline
\end{tabular}

Fonte: Os autores (2015).

Os resultados qualitativos, obtidos a partir da entrevista em profundidade com os profissionais, encontram-se descritos por meio de três quadros síntese contendo as ideias centrais emergentes, trechos dos discursos do sujeito coletivo e a frequência de cada um deles. Os discursos não serão apresentados na íntegra, devido à sua extensão.

No Quadro 1 encontram-se as ideias centrais e seus respectivos discursos referentes aos pontos positivos do IDQ.

Quadro 1 - Ideias Centrais acerca dos pontos positivos do IDQ identificados pelos trabalhadores da saúde da SMS Curitiba, seus respectivos discursos e frequências

\begin{tabular}{|c|c|}
\hline IDEIAS CENTRAIS & DISCURSOS DO SUJEITO COLETIVO \\
\hline \multirow{6}{*}{ IDQ como motivador } & {$[\ldots]$ Quando você trabalha por produtividade [...] você pensa assim... Eu } \\
& tenho tantas metas pra atingir, pra isso eu vou receber um incentivo financeiro. \\
& {$[\ldots]$ ficava mais fácil de atingir a meta e tinha um porque de atingir aquela } \\
& meta. Isso faz com que você tenha o reconhecimento profissional também, \\
& né? [...] Incentiva o funcionário a sempre ter uma melhor qualidade do \\
& trabalho [...] E às vezes o reconhecimento não é só financeiro, [...] mas \\
& sim o reconhecimento de dizer, de dar um certificado [...] Então assim eu \\
& acho que como motivador de equipe funcionava bem, né!? [...] Então, isso \\
& incentivava a gente, né, então hoje com a extinção, a gente tá meio, assim, \\
ai... Se cumprir tudo bem, se não cumprir também tudo bem [...] (13)
\end{tabular}




\begin{tabular}{|c|c|}
\hline $\begin{array}{l}\text { IDQ promovendo maior } \\
\text { qualidade do serviço }\end{array}$ & $\begin{array}{l}\text { [...] a questão maior agora é a questão da qualidade do serviço. } \\
\text { Então o quê que se premia? Se premia o funcionário que trabalha } \\
\text { bem, que cumpre o seu horário, que não tem nenhuma reclamação } \\
\text { da população, que ele participa das decisões da equipe [...] (2) }\end{array}$ \\
\hline $\begin{array}{l}\text { IDQ como ferramenta } \\
\text { de avaliação individual }\end{array}$ & $\begin{array}{l}\text { O ponto positivo pro gestor é que ele era uma ferramenta de avaliação individual } \\
\text { né e não da equipe [...] isso deixava as pessoas [...] sabendo que seriam } \\
\text { avaliadas, então tinha aquele certo receio por parte de algumas pessoas [...] (1) }\end{array}$ \\
\hline
\end{tabular}

Fonte: Os autores (2016).

No Quadro 2 encontram-se as ideias centrais, os discursos e frequências relativos às limitações do IDQ.

Quadro 2 - Ideias Centrais acerca das limitações do IDQ, seus respectivos discursos e frequências

\begin{tabular}{|c|c|}
\hline IDEIAS CENTRAIS & DISCURSOS DO SUJEITO COLETIVO \\
\hline $\begin{array}{l}\text { O IDQ era bom } \\
\text { em teoria, mas não } \\
\text { funcionava na prática }\end{array}$ & $\begin{array}{l}\text { A ideia originalmente era maravilhosa, né? De você poder sentar a cada três } \\
\text { meses e conversar e avaliar o processo de trabalho [...] E assim, eu acho que } \\
\text { tem o seu valor se houvesse uma cobrança verdadeira. Então oh, se você atingiu, } \\
\text { você ganha. Se você não atingiu, você não ganha. [...] mas caiu em desuso [...] } \\
\text { Se o gestor colocasse lá uma nota } 95 \text { pra pessoa né em assiduidade. A pessoa } \\
\text { falta, falta e falta, mas se você não desse dez... Nossa... A gente sabe até hoje de } \\
\text { chefias que respondem processo por conta disso. [...] Porque caiu numa né numa } \\
\text { questão assim de rotina. Não, o IDQ é algo já tá incorporado e pronto, né? [...] } \\
\text { Era dez, dez, dez, dez, dez, assina, carimba e pronto. Pra que? Ele estava vicioso } \\
\text { [...] Até hoje poucos servidores perderam o IDQ e geralmente era por questão de } \\
\text { pontualidade e assiduidade [...] Se você era bem visto pela chefia, você sempre } \\
\text { atingia tudo [...] Mas quando você tinha alguma contradição [...] ela vinha } \\
\text { em cima do IDQ pra te avaliar, então era meio usado também eu achava como } \\
\text { pontos de [...] perseguição. [...] Nós sabemos de histórias, claro, não posso provar, } \\
\text { mas sabemos de histórias que muitos locais criavam os procedimentos [...] (14) }\end{array}$ \\
\hline $\begin{array}{c}\text { Priorização da quantidade } \\
\text { em detrimento } \\
\text { da qualidade }\end{array}$ & $\begin{array}{l}\text { O IDQ ele tinha vários segmentos [...] todas essas avaliações é que formavam } \\
\text { uma nota final pra dar o ponto para o tal do IDQ, né, pra saber se a gente } \\
\text { ganharia ou não um percentual de prêmio [...] Eu não gosto dessa parte de } \\
\text { avaliar o funcionário somente por números. Se você for ver por número, é muito } \\
\text { fácil você entrar no E-Saúde e conseguir registrar vários procedimentos em um } \\
\text { paciente. [...] então a parte qualitativa do IDQ eu acho que fica um pouco } \\
\text { a desejar. Ficar só ligado na quantificação é extremamente perigoso, porque } \\
\text { daí tem muitos profissionais que acabam deixando a qualidade de lado pra se } \\
\text { atingir a quantidade. Quantitativamente eu acho o IDQ inútil. [...] (4) }\end{array}$ \\
\hline
\end{tabular}




\begin{tabular}{|c|c|}
\hline A autoavaliação era ruim & $\begin{array}{l}\text { O ponto negativo era as avaliações como eram feitas e eu acho que a } \\
\text { autoavaliação. Eu acho que ela era muito subjetiva [...] Pra todas as } \\
\text { categorias era a mesma coisa [...] Além disso, desde que eu entrei na } \\
\text { prefeitura nos orientavam assim, antes de eu entrar na gestão: preencha } \\
10 \text { em tudo. [...] a maioria maciça dos servidores preenchem } 10 \text { [...] As } \\
\text { pessoas não queriam se prejudicar [...] E a chefia, por outro lado, eu vejo } \\
\text { que era um instrumento da chefia talvez ali naquele momento cobrar do } \\
\text { funcionário [...] Mas o corre corre do dia a dia das chefias que já tinham } \\
\text { tanta coisa pra fazer, às vezes, não queriam se incomodar com isso (3) }\end{array}$ \\
\hline $\begin{array}{l}\text { O IDQ era usado para } \\
\text { não aumentar os salários }\end{array}$ & $\begin{array}{l}\text { [...] o salário base era baixo, e daí eles deixavam melhorzinho com o } \\
\text { IDQ, né? Se você tem um aumento de salário, isso eles não podem } \\
\text { tirar, então era uma forma de a Prefeitura talvez contornar, né, dar um } \\
\text { aumento de salário, mas não se comprometer e poder tirar a qualquer } \\
\text { momento. [...] Além disso, a pessoa quando se aposenta perde, né (3) }\end{array}$ \\
\hline O IDQ não fazia diferença & $\begin{array}{l}\text { Não sei se agregava muito mais esforço da equipe, entendeu? Então até } \\
\text { acho que não fez tanta diferença na produção o IDQ antes e depois. } \\
\text { [...] quem era comprometido continuou comprometido e quem não } \\
\text { era comprometido continua não sendo comprometido. [...] (2) }\end{array}$ \\
\hline $\begin{array}{l}\text { O IDQ só fez efeito } \\
\text { inicialmente }\end{array}$ & $\begin{array}{l}\text { O IDQ quando ele foi instituído ele teve um objetivo de valorar financeiramente } \\
\text { as equipes e os profissionais que se dispunham a trabalhar em serviços com maior } \\
\text { demanda, mais distante, que tivessem mais dificuldade de lotação de pessoal, } \\
\text { né!? E que desenvolvessem um trabalho de qualidade, atingindo as pactuações, } \\
\text { né!? [...] Inicialmente fez efeito, porque daí as pessoas queriam, né? Ah... Nós } \\
\text { precisamos atingir a meta se não a gente não recebe... Então e no início eram } \\
\text { metas que a gente não atingia realmente, né? [...] As equipes foram adequando e } \\
\text { foram dando conta e não ficou mais tão difícil atingir aquelas metas que tinham } \\
\text { lá. Só que dinheiro ele é bom quando ele é instituído, passou uns meses ele faz } \\
\text { parte da rotina, certo? [...] Mas penso que no decorrer do tempo foi acho que } \\
\text { usado pouco essa ferramenta como uma ferramenta que poderia melhorar mesmo } \\
\text { a qualidade do serviço. Porque era Índice de desenvolvimento da qualidade, né!? } \\
\text { E depois ficou só IDQ e ninguém sabia o que é que era o IDQ, né!? [...] (2) }\end{array}$ \\
\hline $\begin{array}{c}\text { Falhas na avaliação } \\
\text { individual }\end{array}$ & $\begin{array}{l}\text { A avaliação individual de cada profissional, [...] era uma avaliação que } \\
\text { na verdade você tinha muita dificuldade por exemplo que um indivíduo } \\
\text { perdesse o IDQ, porque ela era difícil de ser feita e tirado a nota dele o } \\
\text { suficiente para ele perder um IDQ, né!? Ele perdia IDQ se ele faltasse } \\
\text { não sei quantas vezes. [...]E como valia dinheiro dificilmente a pessoa } \\
\text { olhava pra si e dizia nisso aqui eu mereço cinco, né!? Ou a chefia falava } \\
\text { puxa coitadinha... Ela precisa tanto desses 30\% ou desses } 50 \% \text { e } \\
\text { então isso também pesava na avaliação, mesmo a da chefia [...] (2) }\end{array}$ \\
\hline $\begin{array}{l}\text { O IDQ compunha } \\
\text { uma parte muito } \\
\text { grande do salário }\end{array}$ & $\begin{array}{l}\text { Mas o que eu penso do IDQ que não funcionava bem é que ele } \\
\text { representava uma fatia muito grande do teu vencimento. Então algumas } \\
\text { Unidades recebiam 20, outras recebiam } 30 \% \text { em cima do seu vencimento, } \\
\text { isso era muito grande. Então quando a pessoa perdia, era uma catástrofe, } \\
\text { né?[...] Então ficava algo muito assustador assim [...] (1) }\end{array}$ \\
\hline
\end{tabular}

Fonte: Os autores (2016). 
As ideias centrais, os discursos e frequências referentes às sugestões para melhoria do sistema de incentivo financeiro adotado encontram-se descritos no Quadro 3.

Quadro 3 - Ideias Centrais sobre as sugestões para melhoria

do IDQ, seus respectivos discursos e frequências

\begin{tabular}{|c|c|}
\hline IDEIAS CENTRAIS & DISCURSOS DO SUJEITO COLETIVO \\
\hline $\begin{array}{l}\text { Instituição de avaliação } \\
\text { qualitativa }\end{array}$ & $\begin{array}{l}\text { Daí tem que se pensar, ver uma maneira de se bonificar pelo tipo de } \\
\text { serviço que é feito, pela qualidade, não só a quantidade... (4) }\end{array}$ \\
\hline Mudanças na avaliação & $\begin{array}{l}\text { [...] É uma bonificação pela produtividade do profissional, isso } \\
\text { tem que ser individualizado. Não pode ser pra todo mundo. Se } \\
\text { não de novo... Aquele que faz mais ganha a mesma coisa que } \\
\quad \text { aquele que faz menos. Qual que é o incentivo? [...] (2) }\end{array}$ \\
\hline $\begin{array}{l}\text { Incentivos estruturais } \\
\text { funcionariam melhor }\end{array}$ & $\begin{array}{l}\text { O incentivo é legal para estrutura física, pra manter as } \\
\text { estruturas das Unidades. Mas em salários, eu acho que a gente } \\
\text { tem que ter propostas mais concretas, sabe? [...] (1) }\end{array}$ \\
\hline $\begin{array}{l}\text { Deveria haver } \\
\text { aumento do salário }\end{array}$ & $\begin{array}{l}\text { [...] Eu penso que a Secretaria, um dos pontos falhos da prefeitura é essa } \\
\text { remuneração variável ali né!? Porque você aposenta e você não leva nada } \\
\text { disso, eu acho errado isso, eu acho que a gente teria que contribuir na } \\
\text { Previdência lá na questão da aposentadoria a todos os proventos. [...] (2) }\end{array}$ \\
\hline
\end{tabular}

Fonte: Os autores (2016).

\section{Discussão}

As avaliações de desempenho consistem em dispositivos de tomada de decisões e de definição de políticas de gestão de pessoas, fundamentadas em critérios consensuais e que levam ao julgamento de valor de uma intervenção. $\mathrm{O}$ processo de avaliação é tão importante quanto às conclusões geradas por ele, pois permite a compreensão de necessidades de mudanças (Fontenele, 2010).

A remuneração baseada em desempenho requer seleção cuidadosa dos indicadores em que o desempenho será medido e um projeto cuidadoso de incentivos para que possa alinhar o comportamento de saúde do trabalhador com os objetivos da instituição ou serviços de saúde (Dal Poz; Pierantoni;Varella, 1997;Vujicic; Ohiri; Sparkes, 2009).

Entretanto, a ausência de uma cultura de muitas organizações do setor público no Brasil em estabelecer metas e o predomínio de uma visão avaliativa que privilegia somente a produtividade, muitas vezes se reduzindo a contagem de procedimentos e controle contábil, produz ambiguidades e conflitos no ambiente de trabalho, impedindo que os trabalhadores distingam outros objetivos mais nobres do processo de cuidado à saúde (Fontenele, 2010).

Barreto (2015) explica que, a depender do modelo adotado, o pagamento por performance pode produzir efeitos inesperados ou indesejáveis, motivando comportamentos distorcidos (ignorar importantes tarefas não recompensadas), 'mapismo' 
(fraude na apresentação de relatórios), 'escolha a dedo' (seleção de pacientes com base na facilidade para atingir metas), ampliação das disparidades de recursos entre os mais ricos e os mais pobres e dependência dos incentivos financeiros.

Ditterich e Moysés (2012), ao avaliarem o aspecto do sistema de avaliação de desempenho (IDQ) ser transparente para os profissionais de saúde da SMS de Curitiba, verificaram que a gestão apresenta dificuldades em desvelar os mecanismos de avaliação realizados pela ASL. Dessa forma, isto tende a estimular o distanciamento dos profissionais de saúde, já que estes se percebem não ouvidos em suas sugestões e não participantes das tomadas de decisões, o que pode afetar na satisfação crescente com a organização. Ainda quanto a essa questão, Snyder e Neubauer (2007) defendem que o processo de avaliação não seja somente transparente para os profissionais de saúde, pois os pacientes também devem saber quais as medidas de qualidade a que estão sendo submetidos para que os funcionários recebam os incentivos financeiros.

Observou-se nesta pesquisa que o IDQ foi considerado motivador para o cumprimento das funções no ambiente de trabalho, intensificando a busca pelo alcance de metas e pelo reconhecimento dos gestores, dos demais profissionais e da SMS. Como ponto negativo, evidenciou-se uma dependência dos incentivos para que as metas fossem buscadas, sendo que na sua ausência o comprometimento ficaria reduzido.

Tal entendimento está em consonância com a Teoria de Agência (Jensen; Meckling, 1976), segundo a qual o principal ou contratante delega funções ao agente ou contratado, concedendo-lhe autonomia para tomada de decisão. O agente nem sempre irá buscar atingir os objetivos do principal, por esse motivo seria necessário instituir um sistema de incentivo que direcione o agente aos propósitos do principal.

Neste estudo, os agentes (profissionais de saúde) deixaram claro que para buscar atingir as metas propostas pelo principal (SMS de Curitiba) e sair de sua zona de conforto, o incentivo financeiro seria fundamental, caso contrário, o esforço para atingir os resultados esperados seria reduzido.

Opondo-se a tal entendimento, dados da OCDE (2005) revelam que o impacto do sistema de incentivo sobre a motivação das pessoas apresenta papel secundário, uma vez que possibilidades de promoção e a organização do trabalho seriam mais eficazes. Dados obtidos pela pesquisa do Banco Mundial (2006) também indicam que a estabilidade no emprego, elementos que contribuem para seu crescimento profissional, como disponibilização de cursos e a proximidade do domicílio exercem mais efeito sobre sua motivação do que os salários recebidos e a flexibilidade de seus horários.

Identificou-se ainda que o IDQ foi considerado um instrumento de pressão, de modo que a possibilidade de perda do incentivo seria uma punição para aqueles servidores que não atingissem as metas estipuladas, sendo algo positivo para estimular os profissionais a realizarem suas funções. Porém, ressalta-se que não deve ser apenas um instrumento de punição, mas de diálogo e incentivo.

A promoção do diálogo gerada pelo sistema de incentivo está em consonância com resultados de uma pesquisa realizada pelo Banco Mundial (2006), segundo a qual o processo 
avaliativo do IDQ pode ser mais motivador que a própria recompensa ou punição, uma vez que contribui para estimular o diálogo entre servidores e gestores. Quando um problema é constatado com um membro da equipe, a equipe busca solucioná-lo em conjunto. Em concordância, a OCDE (2005) também defende que o sucesso do sistema de incentivo depende mais da qualidade do processo avaliativo do que do próprio pagamento.

Outro aspecto positivo do IDQ segundo a percepção dos entrevistados refere-se ao fato de estimular a atuação em Unidades de Saúde distantes e situadas em áreas de risco. O uso de incentivos financeiros para este fim tem sido frequente, segundo Campos, Machado e Girardi (2009). Porém, os autores ressaltam que a sua conciliação com estímulos não financeiros, como a oferta de formação permanente e de boas condições de moradia, podem ampliar ainda mais sua eficácia. No caso específico do IDQ, os percentuais pagos são variáveis entre 20 e $50 \%$, de acordo com a dificuldade de lotação da unidade, a rotatividade dos profissionais, a dificuldade de acesso, e a complexidade dos serviços prestados (Marques et al, 2013). O IDQ foi implantado com o objetivo de "[...] estimular e motivar os servidores na busca da melhoria contínua dos serviços prestados na área da saúde, no desempenho de suas atividades individuais e em equipe, viabilizando o atendimento de qualidade à população" (Curitiba, 2005, não paginado).

Magalhães (1998) destaca que a avaliação de desempenho não deve se limitar aos critérios de bonificação dos profissionais, mas sim estimular o comprometimento das equipes com os objetivos da instituição e articular a gratificação ao alcance das metas que assegurem maior eficiência aos serviços de saúde e a maior qualidade dos atendimentos.

Observou-se ainda que, segundo a percepção dos entrevistados, a proposta inicial do IDQ era positiva, pois propiciaria o diálogo entre gestores e profissionais, porém a avaliação virou rotina e surgiram problemas relacionados às notas atribuídas, principalmente na autoavaliação e na avaliação individual. Duas situações opostas foram relatadas: a da atribuição de nota dez para todos na avaliação individual, para evitar problemas com os profissionais, inclusive processos; e a da atribuição de notas ruins pelos gestores com a finalidade de prejudicar funcionários.

Identificou-se, inclusive, a criação de procedimentos não realizados e o seu registro nos sistemas de informação, para obtenção de maiores notas na avaliação da Unidade de Saúde, a qual avalia se as metas pactuadas foram atingidas. Evidencia-se, portanto, a necessidade de maior transparência e imparcialidade nas avaliações realizadas, a fim de que o propósito de incentivar a ampliação da qualidade dos serviços prestados seja de fato atingido.

Foram ainda enfatizados como limitações, os riscos da avaliação quantitativa, que pode levar ao registro de vários procedimentos para um único paciente sem levar em consideração a qualidade com que foram realizados. Ademais, foi relatado que a maioria dos profissionais atribuía a si a nota dez na autoavaliação, independente da forma como tinham realizado seu trabalho, com o único propósito de receber o benefício financeiro.

Em concordância, Oxman e Fretheim (2009) ressaltam que o pagamento por desempenho pode gerar efeitos negativos, incluindo distorções, de modo que ações 
e serviços importantes sejam deixados de lado, selecionando casos de pacientes que permitam que as metas sejam atingidas mais rapidamente.

A autoavaliação seria um momento de reflexão acerca de seu próprio desempenho, porém, conforme evidenciado, não foi utilizada com esse fim, mas apenas como uma forma de ampliar a pontuação do IDQ. Como alternativa, poderia ser viável comparar as notas dadas pelo profissional com as outras três avaliações e, nos casos em que houvesse grandes discrepâncias, promover o diálogo com os servidores a fim de verificar o que de fato estava ocorrendo.

O IDQ buscava atingir dois propósitos:resolver a dificuldade de lotação e permanência dos profissionais em locais de dificil acesso ou com maior grau de complexidade dos serviços prestados; e melhorar a qualidade dos serviços, atingindo as metas pactuadas (Marques et al., 2017). Tais propósitos foram atingidos inicialmente, porém, com o tempo, cumprir as metas existentes e receber o IDQ tornou-se uma rotina, de modo que muitos sequer sabiam o que significava a sigla. Além disso, as avaliações não necessariamente eram realizadas de forma coerente e, posteriormente esse valor foi incorporado ao salário.

Uma pesquisa realizada pelo Banco Mundial (2006) revelou que 90\% dos entrevistados considerava que o IDQ exerceu influência sobre o comportamento dos profissionais quando foi introduzido, sendo que $61 \%$ considerava que ele ainda fazia efeito. Houve, portanto, um possível declínio na eficácia desta ferramenta ao longo do tempo.

A redução dos efeitos pode estar associada ao fato de o IDQ ter se tornado uma rotina, já que pouquíssimos funcionários o perdiam. Segundo dados do Banco Mundial (2006), mais de $90 \%$ deles recebiam a gratificação. Aqueles que o perdiam era devido aos fatores de exclusão, como faltas, penalidades administrativas, atrasos e afastamentos, sendo que em pouquíssimos casos isso ocorria devido às notas das avaliações.

Criticou-se também o fato de que o IDQ seria apenas uma forma de aumentar o salário, sem que este aumento fosse definitivo, uma vez que poderia ser cancelado a qualquer momento, como de fato ocorreu. Para a OCDE (2005), os governos, por vezes, consideram o pagamento de incentivos como uma forma de conter custos salariais, diminuindo a progressão automática pelos níveis salariais, ou ainda, como meio de aumentar o teto salarial global. Percebeu-se, assim, ao longo desta pesquisa, que embora o propósito explícito do IDQ tenha sido ampliar a qualidade dos serviços, por meio do estímulo aos funcionários, na prática, segundo a percepção dos funcionários, estava sendo usado também como meio de reduzir custos salariais.

Neste sentido, Santana (1999) ressalta que o enfoque dos sistemas de incentivo não deve ser a busca por equiparação salarial entre diversos vínculos empregatícios, tampouco compensar salários defasados devido à inflação e ao arrocho salarial, mas sim a melhoria da qualidade dos serviços prestados, com ênfase nas necessidades da população atendida.

Segundo os relatos, as bonificações correspondiam a percentuais elevados e raramente eram perdidas. Desta forma, é possível pressupor que a finalidade seria de satisfazer as necessidades financeiras dos profissionais, sem, no entanto, agregar estes valores ao salário e às futuras aposentadorias. 
Ao comparar os valores do incentivo financeiro do IDQ (20 a 50\% sobre o salário base) com outras experiências em âmbito nacional, constata-se que, de fato, estes são muito maiores que os demais. No caso dos contratos firmados entre uma Secretaria Municipal de Saúde e Organizações Sociais implementados no Rio de Janeiro, por exemplo, o incentivo financeiro concedido aos profissionais de saúde corresponde a até $10 \%$ do salário base de cada membro da equipe (Costa e Silva, 2014). Na FESF-SUS da Bahia os incentivos referentes ao monitoramento da produção e da qualidade atingem até $20 \%$ do salário base (FESF-SUS, 2010). Nos contratos entre Fundação pública de direito privado e as Unidades de Saúde da Estratégia Saúde da Família, em Porto Alegre-RS, o incentivo por desempenho da Estratégia Saúde da Família, atinge até 10\% do salário base (Porto Alegre, 2011).

Segundo dados da OCDE (2005), os pagamentos por desempenho podem ser realizados como acréscimos permanentes aos salários, por mérito; ou como pagamentos únicos que são avaliados periodicamente, precisando ser conquistados em cada processo avaliativo, sendo, portanto, considerados bônus. Estes últimos são empregados com mais frequência, pelo fato de serem mais flexíveis e de não ampliarem os custos fixos com pagamentos. O percentual pago é variável entre os países membros da OCDE, porém, geralmente são valores modestos. Os pagamentos por mérito, em geral, atingem um valor máximo de $5 \%$ sobre o salário base; ao passo que os bônus comumente correspondem a menos de $10 \%$ do salário base para os funcionários públicos; e a cerca de $20 \%$ para os gestores. Nota-se, portanto, que os valores pagos pelo IDQ são maiores que aqueles propostos pela OCDE.

Fekete e Almeida (2000) defendem que os incentivos seriam ganhos extras que teriam por objetivo modificar os trabalhadores para o alcance de determinadas metas ou reforço de determinados comportamentos, mas não deveriam ser adotados como mecanismos de equiparação salarial entre diferentes categorias profissionais ou compensação de defasagens na remuneração dos trabalhadores da saúde.

Reforçou-se a importância de o sistema de incentivo empregado não ser algo automático, incorporado ao salário, mas de fato avaliado de forma transparente e imparcial, para que apenas aqueles que realmente merecem o recebam. As relações de trabalho devem, portanto, ser pautadas na confiança, deve haver diálogo e negociação, priorizando o respeito e a transparência (OCDE, 2005).

Defende-se a adoção de uma avaliação com enfoque qualitativo, para melhoria do sistema de incentivo. Araújo (2010) ressalta que o modelo contratual deve incluir as metas, os meios, o controle e o incentivo; e que para atingir os resultados esperados deve haver a pactuação entre os atores envolvidos acerca do desempenho esperado, da qualidade, dos custos, duração, forma de avaliação e de renovação. Frente aos resultados obtidos nesse estudo, reforça-se a necessidade de pactuação dos níveis de qualidade esperados e não apenas de números.

Foi proposta ainda uma avaliação individualizada. O IDQ pode ser considerado um incentivo extrínseco aos servidores, porém as equipes buscam que seus membros tenham bons resultados, pois $50 \%$ da avaliação individual se fundamenta no desempenho da equipe, sendo 35\% decorrente da avaliação da Unidade de Saúde, em que são analisadas 
as metas atingidas e 15\% da avaliação da comunidade (World Bank, 2006). Tal fato explica o motivo pelo qual alguns profissionais se queixaram da avaliação por equipe, uma vez que quando um indivíduo não coopera, pode prejudicar a avaliação dos demais.

Em contrapartida, segundo dados da OCDE (2005), incentivos direcionados às equipes parecem ter resultados mais positivos que aqueles em âmbito individual. Uma boa avaliação no IDQ é uma preocupação das equipes, as quais buscam resolver os problemas individuais que surgem com seus membros para assegurar bons resultados (World Bank, 2006). A avaliação da equipe estimula, portanto, o trabalho conjunto para atingir as metas, a cooperação, a integração e o diálogo.

Emergiu ainda nos discursos, as diferenças entre incentivos estruturais e individuais. Os primeiros referem-se à concessão de recursos para a Unidade de Saúde realizar melhorias nas condições de trabalho das equipes; ao passo que os segundos relacionam-se ao pagamento dos profissionais composto por uma parte fixa e outra variável (Costa e Silva; Escoval; Hortale, 2014). Segundo o entendimento expresso no discurso, os incentivos estruturais seriam melhores, uma vez que propiciam melhorias no ambiente de trabalho; já os individuais são arriscados, pois estes valores não são incorporados ao salário.

Barreto (2015) afirma que o pagamento por desempenho tem recebido atenção crescente no campo da Pesquisa em Sistemas de Saúde (Health Systems Research) e sido amplamente defendido como estratégia/ferramenta para promover mudanças comportamentais em provedores de serviços de saúde favoráveis a melhores resultados, tanto em nível individual como coletivo. Porém, há que se destacar que o simples fato de premiar ou recompensar os profissionais com base em resultados, não vai garantir automaticamente maior e melhor desempenho na realização do trabalho, bem como provocar mudanças duradouras nas atitudes e comportamentos nos cuidados em saúde (Ditterich, 2011). Uma força de trabalho com bom desempenho é aquela com boa capacidade de respostas, eficiente e que atinge os melhores resultados na saúde em face dos recursos disponíveis e das circunstâncias encontradas. (Ney et al., 2015).

\section{Considerações finais}

Constatou-se que o IDQ inicialmente teve resultados positivos, atingindo os propósitos de solucionar a dificuldade de contratar e reter recursos humanos em locais de difícil acesso, bem como de melhorar a qualidade dos serviços, atingindo as metas pactuadas. Além disso, o incentivo financeiro foi considerado motivador para a realização das funções, ampliando a busca pelo alcance de metas e pelo reconhecimento no ambiente de trabalho. Outro aspecto positivo observado no IDQ refere-se à forma de avalição, a qual era realizada em âmbito coletivo, e não apenas individual, estimulando o sentimento de corresponsabilidade e o trabalho em equipe. Tratava-se de um instrumento de estímulo, de promoção de diálogo entre gestores e profissionais, de redução do absenteísmo, de ampliação da qualidade, e de punição, nos casos em que as metas não fossem atingidas. 
Entretanto, com o tempo a avaliação se tornou apenas mais uma rotina, não sendo realizada da forma como se preconizava em teoria. Os problemas foram relacionados principalmente à avaliação individual e à autoavaliação. Nesta, dificilmente os profissionais atribuíam a si mesmos uma nota inferior a dez, enquanto na individual, por vezes, não havia impessoalidade e transparência. Raramente os profissionais perdiam a bonificação do IDQ, de forma que todos a recebiam independente da qualidade de seus serviços. Outras dificuldades constatadas referem-se à priorização da quantidade na avaliação da Unidade, à fraude de informações para atingir as metas, e ao fato de os incentivos serem empregados como manobra para não aumentar os salários dos servidores, sendo apenas uma bonificação temporária, que não era agregada ao salário nem às futuras aposentadorias.

A avaliação sobre o IDQ ensina importantes lições e aponta algumas perspectivas para os sistemas de incentivos futuros. É importante que a avaliação por desempenho seja realizada com transparência e imparcialidade, a fim de que repercuta na qualidade dos serviços, na motivação dos profissionais e na forma de atendimento aos usuários. Este processo avaliativo não deve gerar conflitos, mas sim promover o diálogo entre profissionais e gestores, para que os acertos sejam recompensados e multiplicados e as falhas sejam corrigidas. Enfatiza-se a necessidade de os profissionais se apropriarem de todas as etapas de pactuação, de avaliação e de desenvolvimento de estratégias para alcançar os resultados esperados.

Os resultados encontrados neste estudo são de grande valia, na medida em que propiciam um maior aprofundamento acerca da temática dos sistemas de incentivo, importantes ferramentas de gestão que têm sido empregadas de forma crescente em âmbito nacional e internacional. Em que pese haja uma limitação, por se tratar de um estudo de caso específico do município de Curitiba e que tais dados não podem ser generalizados, a análise desta experiência pode contribuir para ampliar o entendimento sobre o tema, pelo fato de ser uma das primeiras experiências no âmbito da APS no Brasil. Além disso, são escassos os estudos sobre esta temática em âmbito nacional. Ressalta-se a importância de haver um maior aprofundamento e a divulgação das experiências em curso na gestão municipal da saúde, uma vez que o reconhecimento de suas potencialidades e limitações possibilita aprimorar as políticas existentes, sendo fonte de aprendizado não apenas ao município ao qual se limita, mas também a outras cidades que pretendem implantar novas ferramentas de gestão ou aperfeiçoar aquelas já implantadas.

\section{Referências}

ARAÚJO, Maria Arlete Duarte. Responsabilização pelo controle de resultados no Sistema Único de Saúde no Brasil. Revista Panamericana de Salud Publica, Washington, v. 27, n. 3, p. 230-236, 2010.

AZEVEDO, Jussara de Castilhos Rosa. Contrato Interno de Gestão e Plano Operacional Anual da Secretaria Municipal da Saúde de Curitiba, Paraná: a percepção dos gestores locais e trabalhadores das equipes em saúde. 2009. 80f. Dissertação (Mestrado Profissional de Gestão de Tecnologia em Saúde) - Universidade Federal do Rio Grande do Sul, Rio Grande do Sul, Porto Alegre, 2009. 
AZEVEDO, Jussara de Castilhos Rosa; FAORO, Nilza Teresinha; XAVIER, Erotildes Antunes. Avaliação de desempenho: um instrumento de gestão e democratização nas relações de trabalho. In: BRASIL. Ministério da Saúde. Secretaria de Gestão do Trabalho na saúde (org.). Prêmio InovaSUS: valorização de boas práticas e inovação na gestão do trabalho na saúde. 1. ed. Brasília: Ministério da Saúde, 2013.

BARRETO, Jorge Otávio Maia. Pagamento por desempenho em sistemas e serviços de saúde: uma revisão das melhores evidências disponíveis. Ciência \& Saúde Coletiva, Rio de Janeiro, v. 20, n. 5, p. 1497-1514, 2015.

CAMPOS, Francisco Eduardo de; MACHADO, Maria Helena; GIRARDI, Sábado Nicolau. A fixação de profissionais de saúde em regiões de necessidades. Divulgação em Saúde para Debate, Rio de Janeiro, n. 44, p. 13-24, 2009.

COSTA E SILVA,Vanessa. Terceiro setor e parcerias na saúde: As Organizações Sociais como possibilidades e limites na gerência da Estratégia Saúde da Família. 2014. Tese (Doutorado em Ciências - Saúde Pública) - Escola Nacional de Saúde Pública Sergio Arouca, Rio de janeiro, Rio de Janeiro, 2014.

COSTA E SILVA,Vanessa; ESCOVAL, Ana; HORTALE,Virgínia Alonso. Contratualização na Atenção Primária à saúde: a experiência de Portugal e Brasil. Ciência \& Saúde Coletiva, Rio de Janeiro, v. 19, n. 8, p. 3593-3604, 2014.

CURITIBA. Secretaria Municipal da Saúde. Decreto 1.540 de 22 de novembro de 2005. Institui o Programa de Incentivo ao Desenvolvimento da Qualidade dos Serviços, na Secretaria Municipal da Saúde. Disponível em: $<$ https://leismunicipais.com.br/a/pr/c/curitiba/decreto/2005/154/1540/decreto-n-1540-2005institui-oprograma-de-incentivo-ao-desenvolvimento-da-qualidade-dos-servicos-na-secretaria-municipal-da-saude $>$. Acesso em: 10 set. 2016.

Secretaria Municipal da Saúde. Decreto n 298, de 20 de março de 2015. Curitiba: SMS, 2015a. Disponível em: <http://files.sismuc.org.br/arquivos/leg.-decretos/decreto-298.2015--idq-saude.pdf>. Acesso em: 28 out. 2016.

Secretaria Municipal da Saúde. Decreto n² 299, de 20 de março de 2015. Curitiba: SMS, 2015b. Disponível em: <http://files.sismuc.org.br/arquivos/leg.-decretos/decreto-299.2015--gratificac\%C3\%A3o-a-ser-pagapara-os-servidores-de-func\%C3\%A3o-estrategica-sms.pdf>. Acesso em: 28 out. 2016.

Secretaria Municipal da Saúde. Minuta de Decreto. Curitiba: SMS, 2014. Disponível em: <http://files. sismuc.org.br/arquivos\%5Cdoc.-outros\%5Cminuta-de-decreto-reestrutura-o-programa-de-incenivo-aodesenvolvimento-da-qualidade-dos-servicos.pdf>. Acesso em: 26 out. 2016.

DAL POZ, Mario Roberto; PIERANTONI, Celia Regina; VARELLA, Thereza Christina. Produtividade e desempenho dos recursos humanos nos serviços de Saúde. Washington: OPAS, 1997.

DITTERICH, Rafael Gomes. A contratualização como ferramenta de gestão e organização da atenção primária à saúde: avanços, dificuldades e desafios. 2011. 162f. Tese (Doutorado em Odontologia - Saúde Coletiva) - Pontificia Universidade Católica do Paraná, Paraná, Curitiba, 2011.

DITTERICH, Rafael Gomes; MOYSÉS, Samuel Jorge. A gestão da saúde baseada em resultados e processos de contratualização. In: MOYSÉS, S. J.; GOES, P. S. A. (org.). Planejamento, gestão e avaliação em saúde bucal. São Paulo: Artes Médicas, 2012.

DITTERICH, Rafael Gomes; MOYSÉS, Simone Tetu; MOYSÉS, Samuel Jorge. O uso de contratos de gestão e incentivos profissionais no setor público da saúde. Cadernos de Saúde Pública, Rio de Janeiro, v. 28, n. 4, p. 615-627, 2012.

DUCCI, Luciano. Curitiba firma Contrato de Gestão com metas para a saúde. Revista Brasileira de Saúde da Família, v. 8, n. 14, p. 48-57, 2007.

FEKETE, Maria Christina; ALMEIDA, Márcio José de. Sistemas de incentivo ao trabalho em saúde. Espaço para a saúde, v. 2, n. 1, p. 1-21, 2000.

FESF-SUS. Cartilha do Trabalhador: A Bahia por um novo caminho para a Saúde da Família. Salvador: FESF-SUS, 2010. 
FONTANELLA, Bruno José Barcellos; RICAS, Janete;TURATO, Egberto Ribeiro. Amostragem por saturação em pesquisas qualitativas em saúde: contribuições teóricas. Cadernos de Saúde Pública, Rio de Janeiro, v. 24, n. 1, p. $17-27,2008$.

FONTENELE, Maria de Fátima Marrocos. Gestão do desempenho humano: um estudo de caso em um Hospital Geral de Fortaleza (CE). Ciência \& Saúde Coletiva, v. 15, (Supl. 1), p. 1315-1324, 2010.

JENSEN, Michael C.; MECKLING, William. Theory of the firm: managerial behavior, agency costs and ownership structure. Journal of Financial Economics, v. 3, n. 4, p. 305-360, 1976.

LEFÈVRE, Fernando, LEFÈVRE, Ana Maria Cavalcanti. O discurso do sujeito coletivo: um novo enfoque em pesquisa qualitativa (desdobramentos). Caxias do Sul, SC: EDUSC, 2005.

MAGALHÃES, Maria de Fátima Lage. Recursos humanos e modelo assistencial - um encontro instigante. In: REIS, A. T. et al. Sistema Único de Saúde em Belo Horizonte: reescrevendo o público. São Paulo: Xamã, 1998. p. 193-200.

MARQUES, Adriana Maria Parreiras et al. Avaliação de desempenho e remuneração variável no contexto de gestão por metas pactuadas: A experiência da Secretaria Municipal de Curitiba-PR. 2013. Disponível em: <http://apsredes. org/site2013/experiencia-curitiba/files/2015/01/Curitiba-Docs.pdf>. Acesso em: 04 jan. 2017.

MARTY, Inês Kultchek. Primeiras experiências de contratos de gestão em Curitiba: Secretaria Municipal da Saúde. In: GIACOMINI, C. H. Gestão para resultados em Curitiba: a experiência de contratualização. Curitiba: Instituto Municipal de Administração Pública, 2009.

NEY, Márcia Silveira et al. Sistemas de avaliação profissional e contratualização da gestão na Atenção Primária à Saúde em Portugal. Saúde em Debate, v. 39, n. 104, p. 43-55, 2015.

OCDE - ORGANISATION FOR ECONOMIC CO-OPERATION AND DEVELOPMENT. Paying for performance: policies for government employees. Paris: OECD, 2005.

OXMAN, Andrew D.; FRETHEIM, Atle. Can paying for results help to achieve the Millennium Development Goals? Overview of the effectiveness of results-based financing. Journal of Evidence-Based Medicine, v. 2, n. 2, p. 7083, 2009.

POLI NETO, Paulo et al. Remuneração variável na Atenção Primária à Saúde: relato das experiências de Curitiba e Rio de Janeiro, no Brasil, e de Lisboa, em Portugal. Ciência \& Saúde Coletiva, Rio de Janeiro, v. 21, n. 5, p. 1377$1388,2016$.

PORTO ALEGRE. Lei n 11.062, de 06 de abril de 2011. Porto Alegre, 2011. Disponível em: <http://www2. portoalegre.rs.gov.br/cgi-bin $/ \mathrm{nphbrs} ? \mathrm{~s} 1=000031623 . \mathrm{DOCN} . \& \mathrm{l}=20 \& \mathrm{u}=\% 2 \mathrm{Fnetahtml} \% 2 \mathrm{Fsirel} \% 2 \mathrm{Fsimples} . \mathrm{htm}$ $1 \& \mathrm{p}=1 \mathrm{r}=1 \& \mathrm{f}=\mathrm{G} \& \mathrm{~d}=$ atos $\&$ SECT1 $=$ TEXT\# $\#$ $0>$. Acesso em: 02 jun. 2016.

SANTANA, José Paranaguá de. A gestão do trabalho nos estabelecimentos de saúde: elementos para uma proposta. In: SANTANA, J. P.; CASTRO, J. L. (org.). Capacitação em desenvolvimento de recursos humanos de saúde: CADRHU. Natal: UFRN, 1999. p. 387-400.

SCORTECCI, Catarina. Servidores da Saúde mantém greve; prefeitura vai descontar faltas. Gazeta do Povo, Curitiba, 30 de março de 2015. Disponível em: < http://www.gazetadopovo.com.br/vida-e-cidadania/servidoresda-saude-mantem-greve-prefeitura-vai-descontar-faltas-9brt11is6ikb3817x2xzjnr16>. Acesso em: 30 out. 2016.

SNYDER, Lois; NEUBAUER, Richard L. Pay-for-performance principles that ensure promotion of patientcentered care: An ethics manifesto. Ann Interm Med, v. 147, p. 792-794, 2007.

VUJICIC, Marko; OHIRI, Kelechi; SPARKES, Susan. Working in health: financing and managing the public sector health workforce. Washington: The World Bank, 2009.

WORLD BANK. Brazil Enhancing Performance in Brazil's Health Sector: lessons from innovations in the state of São Paulo and the city of Curitiba. Washington:The World Bank, 2006. 


\title{
Payment for Performance in Primary Health Care in Curitiba-PR: Quality Development Incentive
}

\begin{abstract}
This study aimed to describe and discuss the perception of health workers in the county of Curitiba-PR, Brazil, related to the professional incentives as a tool in the management and organization of Primary Health Care. For this, a descriptive case study was carried out with a qualitative and quantitative approach. Data analysis was carried out seeking to understand the impact of the use of financial incentives in the organization of Primary Health Care in CuritibaPR. We concluded that performance evaluation by means of the incentives offered to workers was as important partner in the search of motivation and commitment of health professionals with the quality of work and the achievement of agreed goals. However, we identified some difficulties regarding the evaluation process, the prioritization of the quantity and the fact that the incentives were used as a maneuver to not increase the salaries of the servers.
\end{abstract}

Keywords: Administration of health services, health management, performance management in health, incentives, pay for performance.

\section{Pago por Desempeño en la Atención Primaria a la Salud en Curitiba-PR: Incentivo al Desarrollo de la Calidad}

\section{Resumen}

El objetivo de este estudio fue describir y discutir la percepción de los trabajadores de la salud en el municipio de Curitiba-PR, Brasil, sobre el uso de incentivos profesionales como herramienta en la gestión y organización de la Atención Primaria a la Salud. Para ello, se realizó un estudio de caso descriptivo con abordaje cualiquantitativo. El análisis de los datos buscó comprender el impacto de la utilización de incentivos financieros en la organización de la Atención Primaria a la Salud en Curitiba-PR. Se concluyó que la evaluación de desempeño con el uso de incentivos ofrecidos a los trabajadores fue importante para ampliar su motivación y compromiso con la calidad del trabajo y el logro de metas pactadas. Sin embargo, se identificaron dificultades en relación al proceso de evaluación, a la priorización de la cantidad y al hecho de que los incentivos se emplean como maniobra para no aumentar los salarios de los servidores.

Palabras clave: Administración de servicios de salud, gestión de la salud, gestión del desempeño en salud, incentivos, pago por desempeño.

\section{Financiamento:}

Chamada Pública 04/2013 - Programa de Pesquisa para o Sistema Único de Saúde: Gestão Compartilhada em Saúde PPSUS - Edição 2012 - Fundação Araucária-PR/SESA-PR/MS-DECIT/ CNPq. 